\title{
Identifying Drug Interactions between Enzalutamide and Complementary Alternative Medications in a Patient with Metastatic Prostate Cancer: A Case Report
}

\author{
Thomas Brownlee, Colleen Olson, and Michelle Deschamps
}

\section{INTRODUCTION}

$\mathrm{P}$ rostate cancer cells are dependent on intratumoral androgens for survival, growth, and proliferation. ${ }^{1}$ For this reason, treatments that reduce the effects of androgens on the prostate, such as enzalutamide and leuprolide, are commonly used to treat prostate cancer and slow disease progression. ${ }^{1}$ Serum free testosterone and prostate-specific antigen (PSA) are often monitored to determine the effectiveness of such treatment. ${ }^{1,2}$

Enzalutamide is a pure androgen receptor signalling inhibitor that is effective for the treatment of metastatic castration-resistant prostate cancer (MCRPC). ${ }^{3,4}$ Enzalutamide is a major substrate of hepatic cytochrome P450 2C8 and 3A4 isozymes (CYP2C8 and CYP3A4), and is commonly subject to pharmacokinetic interactions, which could reduce its effectiveness by changing levels of the drug or active metabolites. ${ }^{5-7}$ Loss of enzalutamide effectiveness could be indicated by a resultant increase in PSA. Because one goal of treating MCRPC is to reduce serum free testosterone to castrate levels, it is also not in the patient's best interest to use products that increase testosterone levels.

To the authors' knowledge, there have been no case reports documenting interactions among enzalutamide, leuprolide, and complementary and alternative medications (CAMs). CAMs are commonly used by patients with cancer and are often perceived to be free from adverse reactions or interactions, a perception that contributes to lack of disclosure of CAM use to health care professionals. ${ }^{6,8,9}$ The lack of disclosure can minimize investigation of adverse effects or interactions associated with CAM use, ultimately endangering patient health. This case report documents outcomes of concurrent use of CAMs, enzalutamide, and leuprolide in a patient with MCRPC.

\section{CASE REPORT}

At the end of May 2017, a middle-aged man (in his late 50 s) presented with a 3-year history of metastatic adenocarcinoma of the prostate with left sacral and acetabular involvement.* His disease was stable, and he was otherwise healthy. Since the cancer diagnosis, he had experienced intermittent back pain, abdominal pain secondary to shingles (early May 2017; resolved before current presentation), intermittent hematuria, and nocturia. No other significant symptoms were documented beyond May 2017.

At the time of presentation, the patient's treatment regimen consisted of the following medications: leuprolide $22.5 \mathrm{mg}$ IM every 3 months (since August 11, 2016), denosumab 120 mg SC every 4 weeks (since January 8, 2016), and enzalutamide $160 \mathrm{mg}$ PO daily (since January 18, 2016) to which he appeared to be adherent. Previously, he had also received degarelix $80 \mathrm{mg}$ SC every 4 weeks (December 28, 2015 , to July 13,2016$)$ and palliative radiotherapy to the left hip and sacroiliac joint.

The patient was seen in late May 2017 in follow-up for rising serum free testosterone and PSA, despite continued androgen deprivation therapy with enzalutamide and leuprolide. From October 20, 2016, to January 13, 2017, serum free testosterone had remained near castrate levels, whereas PSA had risen steadily from $6.67 \mu \mathrm{g} / \mathrm{L}$ to $8.70 \mu \mathrm{g} / \mathrm{L}$ (normal range

*Details not pertinent to the diagnosis or treatment in this case have been omitted to protect patient confidentiality. 
0-4.0 $\mu \mathrm{g} / \mathrm{L})$. By March 14, 2017, serum free testosterone and PSA had risen to $0.97 \mathrm{nmol} / \mathrm{L}$ and $12.16 \mu \mathrm{g} / \mathrm{L}$, respectively (Table 1).

During the appointment in May 2017, it was discovered that the patient was using multiple CAMs. At that time, his oncologist instructed him not to take any testosteronecontaining products. At the oncologist's request, pharmacy staff met with the patient to discuss the CAMs and agreed to conduct research on each product being used and to offer a recommendation to be discussed in a follow-up interview. During the course of this research, the patient discontinued all CAMs and continued androgen deprivation therapy as prescribed by his oncologist.

Most of the CAMs being used by the patient were oral products containing numerous herbal ingredients (listed without quantities) that were extemporaneously compounded and dispensed by an alternative medicine practitioner. Seven products were also described by the patient as homeopathic. After analyzing each container, it was determined that the patient was taking 119 CAMs in total (Table 2).

Enzalutamide and leuprolide were initially considered as potential sources of interactions with the CAMs. However, leuprolide is not metabolized by cytochrome $\mathrm{P} 450$ enzymes and has low protein binding, so interactions with this drug are not expected and were not investigated further. A literature search of Ovid MEDLINE, Embase, PubMed, and Google Scholar from inception to August 2017 using the search terms "enzalutamide" and "herb" revealed no case reports or pharmacokinetic studies of concurrent use of the CAMs identified in this case and enzalutamide. However, multiple studies were found confirming changes in enzalutamide concentration when used concurrently with known CYP2C8 and CYP3A4 inducers and inhibitors, which alludes to the potential of CAMs with similar metabolism to cause clinically significant drug interactions. ${ }^{7,10,11}$ A review of various drug interaction resources, including the Natural Medicines database, the Lexicomp Interactions database, and Stockley's Drug Interactions, revealed possible interactions between 17 of the CAMs and enzalutamide, with differing levels of evidence. The interactants identified were activated charcoal, Aloe, black walnut, garlic, goldenseal, licorice, Echinacea, cat's claw, Boswellia, Gingko biloba, Rhodiola, Berberis vulgaris, milk thistle, guggul, sage, Turkish rhubarb, and Panax ginseng. ${ }^{12-14}$ These interactions are mediated primarily by the CYP3A4 isozyme; however, there are some exceptions, such as activated charcoal, which may reduce or prevent drug absorption (Table 3). ${ }^{12}$ Agents that may negatively affect disease control by increasing testosterone were also identified, including ginger, chondroitin, licorice, Tribulus terrestris, clove, and Panax ginseng. ${ }^{12}$ Furthermore, both arsenic trioxide and leuprolide carry a risk of causing QTc prolongation

\section{Table 1. Patient's Disease Markers, Adapted from Bloodwork Flow Sheet in Electronic Chart}

\begin{tabular}{lcc} 
Date & $\begin{array}{c}\text { Free } \\
\text { Testosterone } \\
(\mathbf{n m o l} / \mathbf{L})\end{array}$ & $\begin{array}{c}\text { Prostate- } \\
\text { Specific Antigen } \\
(\boldsymbol{\mu} \mathbf{g} / \mathbf{L})\end{array}$ \\
\hline October 20, 2016 & $<0.42$ & 6.67 \\
November 21, 2016 & $<0.42$ & 6.70 \\
December 20, 2016 & $<0.42$ & 9.59 \\
January 13, 2017 & $<0.42$ & 8.70 \\
February 11, 2017 & 0.52 & 10.23 \\
March 14, 2017 & 0.97 & 12.16 \\
April 22, 2017 & 0.94 & 14.20 \\
May 23, 2017 & 0.46 & 15.01 \\
June 20, 2017 & 0.67 & 17.51 \\
June 26, 2017 & 0.59 & 17.75 \\
July 10, 2017 & 0.58 & 18.62 \\
August 8, 2017 & $<0.42$ & 22.64 \\
August 21, 2017* & 1.14 & 29.09 \\
October 13, 2017† & $<0.42$ & 35.1 \\
*The patient discontinued enzalutamide about 7 days before \\
bloodwork performed on August 21, 2017. The patient was \\
asymptomatic. \\
tOn October 13, 2017, the patient declined further computed \\
tomography. The patient was asymptomatic.
\end{tabular}

(highest risk and moderate risk categories, respectively), and together they have an additive risk of QTc prolongation. ${ }^{13}$

On the basis of these findings, it was recommended that the patient discontinue all products that might negatively affect disease control by potentially interacting with enzalutamide or increasing serum testosterone. Several products with no evidence of a drug interaction or testosterone-augmenting effect were also discontinued, because they were formulated in combination with the agents listed in Table 3. This left only a short list of products to be continued (Box 1). The rationale for continuing these products included indications for bone health, lack of drug interactions or testosterone-augmenting effect, and patient preference.

Bloodwork on August 8, 2017, following discontinuation of CAMs for at least 28 days, revealed serum free testosterone returning to near-castrate levels, whereas PSA had risen to $22.64 \mu \mathrm{g} / \mathrm{L}$. On the same date, his creatinine clearance was 108 $\mathrm{mL} / \mathrm{min}$ (Cockcroft-Gault equation), and the results of liver function tests were normal. At this time, the patient reported musculoskeletal pain, which resolved on its own. On both August 21 and October 13, the patient claimed to be asymptomatic, although the trend of rising PSA continued, reaching a peak of $35.1 \mu \mathrm{g} / \mathrm{L}$; testosterone remained near castrate levels. No computed tomography (CT) was performed between CAM discontinuation in May 2017 and the time of writing (late 2017). On October 13, the patient declined further CT and communicated his decision to discontinue all therapies. The patient discontinued enzalutamide about 1 week before his appointment on August 21, 2017. 
This single copy is for your personal, non-commercial use only.

For permission to reprint multiple copies or to order presentation-ready copies for distribution, contact CJHP at publications@cshp.ca

Table 2. List of Ingredients in Patient's Herbal/Alternative Medications*

\begin{tabular}{|c|c|c|}
\hline Activated charcoal & Cypress & Milk thistle \\
\hline Adscendes [sic] root & Dandelion & Multivitamin \\
\hline Aele [sic] marmelos & Dong Qui [sic] & Neem leaves powder \\
\hline Ajwon [sic] & Echinacea & Nutmeg extract \\
\hline Allium sativum & Ferrous bisglycinate & Omega-3 EPA + DHA \\
\hline Aloe vera & Frankincense extract & Pau d'Arco \\
\hline Amaltas powder & Garcinia cambogia & Pearl powder \\
\hline Angelica sinses [sic] & Garlic & Pearls \\
\hline Annona muricata & Ginger root & Peom [sic] root \\
\hline Anti-oxidants essential oil & Gingko biloba extract & Peony root \\
\hline Apple cider vinegar & Ginseng & Piper longum \\
\hline Arjuna Terminalia [sic] & Glucosamine & Poria cocos \\
\hline Arkarkara root powder & Goksura powder & Probiotic \\
\hline Arsenic trioxide & Golden seal & Psyllium \\
\hline Arsenicum album & Grape seed extract & Punctured vine extract \\
\hline Ashwaganda [sic] & Green tea & Rhodiola \\
\hline Asparagus & Guar gum & Sage \\
\hline Astralagus [sic] root & Guggul & Sanicle tincture \\
\hline Basil extract & Gymneme [sic] sylvestre leaves powder & Sarphankha \\
\hline Berberis vulgaris & Hadjora & Sarsaparilla \\
\hline Black musli root powder & Hawthorn & Saw palmetto \\
\hline Black walnut hull & Hekla lava & Seabuk thorne [sic] extract \\
\hline Boswellia & Honey goat weed powder & Shilajit powder \\
\hline Burdock & Ipecha [sic] & Sida cordifolia \\
\hline Calcium & Juniper berries & Tracanthus [sic] gum \\
\hline Calendula & Kachnara bark & Tribulus terrestris \\
\hline Caraway & Kalmeg & Triphala \\
\hline Carcinosium [sic] & Kutki & Tulsi \\
\hline Cardamom & Lavendulla [sic] extract & Turkish rhubarb \\
\hline Catnip & Lemongrass extract & Turmeric \\
\hline Cat's claw & Licorice root & Utangan powder \\
\hline Cayenne pepper & Long pepper & Vital [sic] \\
\hline Chaste tree berries & Lycopene & Vitamin C \\
\hline Chicory & Ma Huang & Vitamin D \\
\hline Chinese skullcap & Magnesium & White willow bark \\
\hline Chondroitin & Magnesium glycinate & Wild yam root \\
\hline Cinnamomum zeylanicum & Majuphal & Withinia semniflora [sic] \\
\hline Cinnamon extract & Manjistha & Worm wood \\
\hline Clove extract & Mezereum & Yohimbine bark powder \\
\hline \multicolumn{3}{|l|}{ Coccap [sic] } \\
\hline \multicolumn{3}{|l|}{ Coral mineral } \\
\hline
\end{tabular}

\section{DISCUSSION}

CAMs are widely used by patients with cancer, and their popularity is increasing worldwide. ${ }^{6,9,15,16}$ The public generally considers these agents to be safe and nontoxic, which means that potentially modifying effects on chemotherapy or other cancer treatment are often overlooked. ${ }^{6,16}$ Herbal supplements may compromise the therapeutic efficacy or safety profile of chemotherapy by interacting with the pharmacokinetics of anticancer drugs. ${ }^{6,16}$ Additionally, CAMs often lack premarket demonstration of safety and efficacy, quality control in manufacturing and labelling, and disclosure of usage to health care professionals, all of which contribute to the unpredictability of interactions between CAMs and cancer therapies. ${ }^{7,9,16}$

In the case reported here, elevation of serum free testosterone and PSA after initiation of several CAMs was observed in a patient who had been previously stable on androgen deprivation therapy. The probability of a drug interaction was assessed using the Drug Interaction Probability Scale (DIPS), a tool for evaluating the potential of a drug interaction in 
This single copy is for your personal, non-commercial use only.

For permission to reprint multiple copies or to order presentation-ready copies for distribution, contact CJHP at publications@cshp.ca

Table 3. Summary of Drug Interactions with Enzalutamide and/or Leuprolide*

\begin{tabular}{|c|c|c|c|c|}
\hline Drug & $\begin{array}{l}\text { Interaction } \\
\text { Ratingt }\end{array}$ & $\begin{array}{l}\text { Severity‡ and } \\
\text { Likelihood }\end{array}$ & Level of Evidence & Details \\
\hline Activated charcoal & Moderate & Moderate, probable & D (theoretical) & May reduce or prevent absorption of enzalutamide \\
\hline Black walnut & Moderate & Moderate, possible & $\mathrm{D}$ (theoretical) & $\begin{array}{l}\text { Concomitant oral administration may cause } \\
\text { precipitation of some drugs }\end{array}$ \\
\hline Garlic & Moderate & Moderate, possible & B (PK study) & $\begin{array}{l}\text { Inducer of CYP3A4, which could reduce levels of } \\
\text { enzalutamide }\end{array}$ \\
\hline Goldenseal & Moderate & Moderate, possible & B (PK study) & $\begin{array}{l}\text { Inhibitor of CYP3A4, which could increase levels } \\
\text { of enzalutamide }\end{array}$ \\
\hline Licorice & Moderate & Moderate, possible & $\begin{array}{l}\text { B (PK study; CYP3A4) } \\
\text { D (in vitro evidence; } \\
\text { CYP2C8) }\end{array}$ & $\begin{array}{l}\text { Inducer of CYP3A4, which could reduce levels of } \\
\text { enzalutamide } \\
\text { Inhibitor of CYP2C8, which could increase levels } \\
\text { of enzalutamide }\end{array}$ \\
\hline Echinacea & Moderate & Moderate, possible & B (PK study) & $\begin{array}{l}\text { Inducer of CYP3A4, which could reduce levels } \\
\text { of enzalutamide }\end{array}$ \\
\hline Cat's claw & Moderate & Moderate, possible & D (in vitro evidence) & $\begin{array}{l}\text { Inhibitor of CYP3A4, which could increase levels } \\
\text { of enzalutamide }\end{array}$ \\
\hline Boswellia & Moderate & Moderate, possible & $\mathrm{D}$ (in vitro evidence) & $\begin{array}{l}\text { Inhibitor of CYP3A4, which could increase levels } \\
\text { of enzalutamide }\end{array}$ \\
\hline Gingko biloba & Moderate & Moderate, possible & $\begin{array}{l}\text { B (nonrandomized } \\
\text { clinical trial) }\end{array}$ & $\begin{array}{l}\text { Conflicting evidence as to whether Gingko biloba } \\
\text { induces or inhibits CYP3A4 }\end{array}$ \\
\hline Rhodiola & Moderate & Moderate, possible & $\mathrm{D}$ (in vitro evidence) & $\begin{array}{l}\text { Inhibitor of CYP3A4, which could increase levels } \\
\text { of enzalutamide }\end{array}$ \\
\hline Berberis vulgaris & Moderate & Moderate, possible & D (theoretical) & $\begin{array}{l}\text { Inhibitor of CYP3A4, which could increase levels } \\
\text { of enzalutamide }\end{array}$ \\
\hline Milk thistle & Moderate & Moderate, possible & $\mathrm{D}$ (in vitro evidence) & $\begin{array}{l}\text { Inhibitor of CYP3A4, which could increase levels of } \\
\text { enzalutamide } \\
\text { Inhibits mitogenic signalling pathways involved in } \\
\text { proliferation of androgen-dependent cancer cells }\end{array}$ \\
\hline$\overline{\text { Guggul }}$ & Moderate & Moderate, probable & $\mathrm{D}$ (in vitro evidence) & $\begin{array}{l}\text { Inducer of CYP3A4, which could reduce levels of } \\
\text { enzalutamide }\end{array}$ \\
\hline Sage & Moderate & Moderate, possible & $\mathrm{D}$ (in vitro evidence) & $\begin{array}{l}\text { Inhibitor of CYP3A4, which could increase levels } \\
\text { of enzalutamide }\end{array}$ \\
\hline Panax ginseng & Moderate & Moderate, probable & $\begin{array}{l}\text { B (nonrandomized } \\
\text { clinical trial) }\end{array}$ & $\begin{array}{l}\text { Inhibitor of CYP3A4 which could increase levels of } \\
\text { enzalutamide } \\
\text { Panax ginseng may increase levels of testosterone } \\
\text { in the blood }\end{array}$ \\
\hline Turkish rhubarb & Moderate & Moderate, probable & D (theoretical) & $\begin{array}{l}\text { Might reduce absorption of enzalutamide because } \\
\text { of reduced GI transit time }\end{array}$ \\
\hline Arsenic trioxide & Major & High, probable & B (epidemiologic study) & $\begin{array}{l}\text { Known high-risk QT-prolonging agent; additive } \\
\text { QT-prolonging effect with leuprolide }\end{array}$ \\
\hline$\overline{A l o e}$ & Moderate & Moderate, possible & D (theoretical) & $\begin{array}{l}\text { Aloe can reduce drug absorption of some drugs due } \\
\text { to decreased GI transit time }\end{array}$ \\
\hline Clove & Unknown & Unknown & D (animal studies) & Increased levels of testosterone \\
\hline Ginger & Unknown & Unknown & D (animal studies) & Increased levels of serum testosterone \\
\hline Chondroitin & Unknown & Unknown & $\begin{array}{l}\text { B (nonrandomized } \\
\text { clinical trial) }\end{array}$ & $\begin{array}{l}\text { May be associated with spread or recurrence of } \\
\text { prostate cancer }\end{array}$ \\
\hline Tribulus terrestris & Unknown & Unknown & $\begin{array}{l}\text { D (animal studies) } \\
\text { B (nonrandomized } \\
\text { clinical trial) }\end{array}$ & $\begin{array}{l}\text { May increase levels of testosterone } \\
10-20 \mathrm{mg} / \mathrm{kg} \text { daily for } 4 \text { weeks did not increase } \\
\text { serum testosterone in young, healthy men }\end{array}$ \\
\hline
\end{tabular}

$\mathrm{CYP}=$ cytochrome P450, GI = gastrointestinal, $\mathrm{PK}=$ pharmacokinetic

*Only interactions rated moderate to severe were included in this analysis. Numerous other agents received minor interaction ratings.

tInteraction ratings: major = do not use in combination, contraindicated, strongly discourage patients from using this combination, a serious adverse outcome could occur; moderate = use cautiously or avoid combination, warn patients that a significant interaction or adverse outcome could occur; minor = be aware that there is a chance of an interaction, advise patients to watch for warning signs of a potential interaction. \#Severity ratings: high = life-threatening or severe impairment possible; moderate = moderate impairment or significant discomfort possible; mild = mild impairment or mild discomfort possible; insignificant = drug levels may be affected, but a clinically significant interaction is not likely. 


\section{Box 1. Drugs with No Hormonal or CYP 3A4/2C8 Activity}

\section{Omega-3 fatty acids (EPA + DHA)}

Multivitamin

Probiotic

Calcium

Vitamin D

Ferrous bisglycinate

Ipecha [sic]

Hekla lava

Carcinosium [sic]

CYP 3A4/2C8 = cytochrome P450 3A4 and 2C8 isozymes,

$\mathrm{DHA}=$ docosahexaenoic acid, EPA = eicosapentaenoic acid.

patients. ${ }^{17}$ The DIPS consists of 10 questions about potential drug interactions, with the results being used to estimate the probability of an interaction (Table 4). In this case, the calculated DIPS score was 5 , which suggested a probable drug interaction between enzalutamide and the CAMs that the patient was using. ${ }^{17}$ Notably, the DIPS tool was created to predict the probability of an interaction between 2 drugs, and as such there are limitations to its use in this case; however, no tool evaluating drug interactions among multiple agents (including CAMs) was found.

This case report has several limitations. First, the study was limited by its reliance on subjective information provided by the patient. Also, although serum free testosterone returned to near-castrate levels upon discontinuation of CAMs, the PSA continued to rise. PSA lacks specificity and may increase for reasons other than prostate cancer, such as infection, inflammation, and benign prostate hyperplasia, ${ }^{18}$ which effectively does not rule out the possibility of CAM-drug interactions; however, to the authors' knowledge, the patient did not have any of these conditions. Finally, the large number of CAMs used, the lack of information about doses, the potential for multiple interactions, and the lack of good-quality evidence confirming interactions between CAMs and enzalutamide made it difficult to confirm whether the CAMs had caused clinically significant interactions. Many of the interactions identified were theoretical or based on in vitro evidence, which often does not translate to clinical significance. ${ }^{6}$

\section{CONCLUSION}

CAM usage among cancer patients is growing increasingly popular. CAMs are commonly perceived to be nontoxic, leading to a lack of disclosure. For health care professionals, it is important to identify CAM usage when obtaining patients' medication history and to educate patients about the risks of using CAMs concurrently with cancer therapies. Providing appropriate education can be difficult, as there is little clinical evidence outlining interactions between CAMs and cancer therapies. For this reason, when health care professionals are

\section{Table 4. Scoring Chart for Drug Interaction Probability Scale}

\begin{tabular}{lc} 
Score & Interpretation \\
\hline$>8$ & Drug interaction is highly probable \\
$5-8$ & Drug interaction is probable \\
$2-4$ & Drug interaction is possible \\
$<2$ & Drug interaction is doubtful \\
\hline
\end{tabular}

making recommendations, they commonly rely upon in vitro data and the theoretical risk based on mechanisms of action. Because many patients using CAMs strongly believe in the benefits of these agents, pharmacists recommending discontinuation of such products on the basis of weak evidence risk losing the patient's trust and must be careful to present objective, balanced information. Further study identifying and measuring the significance of interactions among CAMs, enzalutamide, and other cancer therapies is needed.

\section{References}

1. Rove KO, Debruyne FM, Djavan B, Gomella LG, Koul HK, Lucia MS, et al. Role of testosterone in managing advanced prostate cancer. Urology. 2012;80(4):754-62.

2. von Klot CA, Kuczyk MA, Boeker A, Reuter C, Imkamp F, Herrmann TRW, et al. Role of free testosterone levels in patients with metastatic castrationresistant prostate cancer receiving second-line therapy. Oncol Lett. 2017; 13(1):22-8.

3. Shore ND, Chowdhury S, Villers A, Klotz L, Siemens DR, Phung D, et al. Efficacy and safety of enzalutamide versus bicalutamide for patients with metastatic prostate cancer (TERRAIN): a randomised, double-blind, phase 2 study. Lancet Oncol. 2016;17(2):153-63.

4. Penson DF, Armstrong AJ, Concepcion R, Agarwal N, Olsson C, Karsh L, et al. Enzalutamide versus bicalutamide in castration-resistant prostate cancer: the STRIVE trial. J Clin Oncol. 2016;34(18):2098-106.

5. Enzalutamide. In: Lexicomp Online ${ }^{\circledR}$, Lexi-Drugs Online ${ }^{\circledR}$ [online database]. Hudson (OH): Wolters Kluwer Clinical Drug Information, Inc; [cited 2017 Jul 26]. Accessed through institutional subscription. Subscription required to access content.

6. Goey AKL, Beijnen JH, Schellens JHM. Herb-drug interactions in oncology. Clin Pharmacol Ther. 2014;95(4):354-5.

7. Stepney R, Lichtman SM, Danesi R. Drug-drug interactions in older patients with cancer: a report from the 15th Conference of the International Society of Geriatric Oncology, Prague, Czech Republic, November 2015. Ecancermedicalscience. 2016;10:611.

8. Poonthananiwatkul B, Howard RL, Williamson EM, Lim RHM. Cancer patients taking herbal medicines: a review of clinical purposes, associated factors, and perceptions of benefit or harm. J Ethnopharmacol. 2015;175: 58-66.

9. Davis EL, Oh B, Butow PN, Mullan BA, Clarke S. Cancer patient disclosure and patient-doctor communication of complementary and alternative medicine use: a systematic review. Oncologist. 2012;17(11):1475-81.

10. Gibbons JA, de Vries M, Krauwinkel W, Ohtsu Y, Noukens J, van der Walt JS, et al. Pharmacokinetic drug interaction studies with enzalutamide. Clin Pharmacokinet. 2015;54(10):1057-69.

11. Del Re M, Fogli S, Derosa L, Massari F, De Souza P, Crucitta S, et al. The role of drug-drug interactions in prostate cancer treatment: focus on abiraterone acetate/prednisone and enzalutamide. Cancer Treat Rev. 2017; 55:71-82.

12. Interaction checker. In: Natural medicines [online database]. Stockton (CA): Therapeutic Research Center; 2017 [cited 2017 Jul 26]. Available from: https://naturalmedicines.therapeuticresearch.com/. Subscription required to access content. 
13. Lexicomp Online ${ }^{\circledR}$, Interactions ${ }^{\circledR}$ [online database]. Hudson $(\mathrm{OH})$ : Wolters Kluwer Clinical Drug Information, Inc; [cited 2017 Jul 26]. Accessed through institutional subscription. Subscription required to access content.

14. Preston CL, editor. Stockley's Drug Interactions [online database]. London: The Pharmaceutical Press; 2016 [cited 2017 Jul 27]. Available from: https://about.medicinescomplete.com/publication/stockleys-druginteractions/. Subscription required to access content.

15. Ebel MD, Rudolph I, Keinki C, Hoppe A, Muecke R, Micke O, et al. Perception of cancer patients of their disease, self-efficacy and locus of control and usage of complementary and alternative medicine. J Cancer Res Clin Oncol. 2015;141(8):1449-55.

16. Tascilar M, de Jong FA, Verweij J, Mathijssen RHJ. Complementary and alternative medicine during cancer treatment: beyond innocence. Oncologist. 2006;11(7):732-41.

17. Horn JR, Hansten PD, Chan LN. Proposal for a new tool to evaluate drug interaction cases. Ann Pharmacother. 2007;41(4):674-80.

18. Prostate-specific antigen (PSA) test. Bethesda (MD): National Cancer Institute; [cited 2018 Jul 17]. Available from: https://www.cancer.gov/types/ prostate/ psa-fact-sheet
Thomas Brownlee, BSP, was, at the time this report was prepared, a candidate in the Bachelor of Science in Pharmacy program, University of Saskatchewan, and a pharmacy summer student with the Saskatchewan Cancer Agency, Saskatoon, Saskatchewan. He is now completing a pharmacy practice residency with Alberta Health Services - Calgary Zone.

Colleen Olson, BA, BSP, is with the Saskatchewan Cancer Agency, Saskatoon, Saskatchewan.

Michelle Deschamps, BSP, MSc, is with the Saskatchewan Cancer Agency, Saskatoon, Saskatchewan.

Competing interests: Michelle Deschamps has received personal fees from Novartis and Gilead for service on various advisory boards, unrelated to this case report. No other competing interests were declared.

\section{Address correspondence to:}

Thomas Brownlee

Alberta Health Services-South Health Campus

4448 Front Street SE

Calgary AB T3M 1M4

e-mail: thomas.brownlee@albertahealthservices.ca

Funding: None received.

\section{ON THE FRONT COVER}

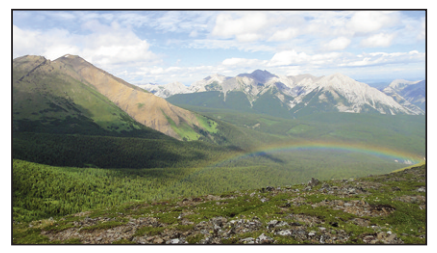

\section{Centennial Ridge Kananaskis, Alberta}

This issue's cover photograph was taken in July 2014 on the Centennial Ridge Trail (with a Sony Cyber-Shot Digital Still Camera) by June Chen, who was then a student pharmacist. To June's disappointment, strong winds and pelting rain forced the unprepared hiker to turn back and forgo the summit of Mount Allan. During her descent, the storm passed, leaving a rainbow in its wake. Three years later, on Canada's 150th anniversary, June returned to complete the hike, but now as a clinical pharmacist working at the Mazankowski Alberta Heart Institute.

The CJHP would be pleased to consider photographs featuring Canadian scenery taken by CSHP members for use on the front cover of the Journal. If you would like to submit a photograph, please send an electronic copy (minimum resolution $300 \mathrm{dpi}$ ) to publications@cshp.ca. 